\title{
Comparison of the Stress Corrosion Cracking Behaviour of AISI 304 Pipes Welded by TIG and LBW
}

\author{
Ji-Jin Xu ${ }^{1}$. Shuai Wang ${ }^{1} \cdot$ Ze Chai $^{1} \cdot$ Chun Yu ${ }^{1}$. Jun-Mei Chen ${ }^{1} \cdot$ Hao Lu ${ }^{1}$
}

Received: 28 April 2020 / Revised: 10 June 2020 / Accepted: 14 July 2020 / Published online: 1 September 2020

(c) The Chinese Society for Metals (CSM) and Springer-Verlag GmbH Germany, part of Springer Nature 2020

\begin{abstract}
The stress corrosion cracking (SCC) behaviour of AISI 304 pipe girth welds which were welded by a single-pass laser beam welding (LBW) and a multi-pass tungsten inert gas welding (TIG), respectively, was studied by the slow strain rate tests combined with the electrochemical corrosion tests. The results show that fracture of both the TIG joint and LBW joint occurs in the heat-affected zone (HAZ). According to the electron-backscattered diffraction observation of the microstructures, comparison of potentiodynamic polarization curves and X-ray photoelectron spectroscopy analysis of corrosion products on HAZs of the two joints after the electrochemical tests, the LBW joint exhibits better SCC resistance than the TIG joint in corrosion environments, due to the synthetic effect of more $\mathrm{Cr}_{2} \mathrm{O}_{3}$ in corrosion products, finer grains, lower residual strain and higher $\delta$-ferrite content in its HAZ. Although the TIG joint has better mechanical property, considering lower SCC susceptibility and higher production efficiency of the LBW joint, the LBW promisingly replaces the TIG for welding of AISI 304 pipes in the nuclear power industry.
\end{abstract}

Keywords Laser beam welding $\cdot$ Slow strain rate test $\cdot$ Stress corrosion cracking $\cdot$ Tungsten inert gas welding $\cdot$ AISI 304 stainless steel

\section{Introduction}

Due to the excellent weldability, high-temperature performance and corrosion resistance, AISI 304 austenitic stainless steel has been widely used in various fabrication industries as a structural material, especially in the nuclear power industry [1]. Stainless steel pipes made of AISI 304 are commonly welded by using tungsten inert gas (TIG) welding and laser beam welding (LBW). TIG welding is a conventional arc technique and now in widespread use, but requires a complicated multi-pass process when jointing plates with large thicknesses [2]. In contrast, LBW involving

Available online at http://link.springer.com/journal/40195.

Ji-Jin Xu

xujijin_1979@sjtu.edu.cn

Chun $\mathrm{Yu}$

yuchun1980@sjtu.edu.cn

1 Shanghai Key Laboratory of Materials Laser Processing and Modification, School of Materials Science and Engineering, Shanghai Jiao Tong University, Shanghai 200240, China a straightforward single-pass process has higher productivity and welding efficiency, lower heat input, smaller heataffected zone (HAZ), deeper penetration and excellent welding quality $[3,4]$.

It is a well-known fact that corrosion resistance of a welding joint depends mainly on the welding technique used because in a specific welding process, the HAZ inevitably undergoes plastic deformation resulting in the variation of the microstructures and introduction of residual stresses [5]. The effects of LBW and TIG on corrosion behaviour of welding joints have been studied by many researchers. Abraham et al. $[6,7]$ reported that the LBW joint showed higher corrosion resistance than the TIG joint for nickelbase alloys based on the electrochemical measurements. The same result was also obtained in the application of duplex stainless steels by Mourad et al. [8]. While Orsi et al. [9] discovered that the TIG welding provided higher resistance to corrosion than LBW in titanium alloys. Therefore, a comparative study on corrosion behaviour of AISI 304 pipes still needs to be conducted. Moreover, stress corrosion cracking (SCC) is a primary failure mode for welded joints applied in the nuclear power industry. The above studies mainly 
focused on the corrosion resistance while ignoring the effect of stress, which deserves more attention.

In order to investigate the combined effect of corrosive medium and stress, SCC susceptibility is evaluated by using the slow strain rate test (SSRT). Xie et al. [10] investigated the SCC behaviour of the solution-treated and cold-drawn 316 austenitic stainless steels in a simulated pressurized water reactor (PWR) environment and abnormal water. $\mathrm{Lu}$ et al. [11] studied the effect of laser shock peening impacts with different pulse energies on the SCC of AISI 304 stainless steels. Tiedra et al. [12] assessed the effect of welding on the SCC behaviour of prior cold-worked AISI 316L by using SSRT, and the results showed that the combined effect of prior cold work and welding did not give rise to SCC because the degree of sensitization induced in the HAZ was insufficient to direct the crack growth. Most studies mainly evaluated the stress corrosion properties of the base materials (BMs), and however, rarely focused on the SCC behaviour of the welded joints. For the AISI 304 stainless steel thick-walled pipes of interest, a comparative study of the effects of the multi-pass TIG and single-pass LBW on SCC has not yet been reported.

Our previous work demonstrated that the LBW is more advantageous than the TIG for the welding of AISI 304 stainless steel pipes, because the former produces lower residual stresses, smaller deformation and higher production efficiency [13]. In order to evaluate the feasibility of LBW replacing TIG in nuclear power plants, further investigations need to be carried out. Here, we carried out a comparative study on the corrosion behaviour of AISI 304 pipes girth welds produced by the TIG and LBW, respectively. This work has the following results: (1) Although the TIG joint has better mechanical property, the LBW joint presents higher SCC resistance than the TIG joint in the simulated PWR environment, which is attributed to more $\mathrm{Cr}_{2} \mathrm{O}_{3}$ in corrosion products, finer grains, lower residual strain and higher $\delta$-ferrite content in the HAZ; (2) In terms of the SCC susceptibility, the residual stress, deformation and production efficiency, the LBW is more advantageous than the TIG for the welding of AISI 304 stainless steel pipes in the nuclear power industry.

\section{Experimental}

\subsection{Materials and Welding Process}

AISI 304 stainless steel pipes with a dimension of $\Phi 89 \mathrm{~mm} \times 250 \mathrm{~mm} \times 14.5 \mathrm{~mm}$ were chosen in this study. The joints were fabricated by the multi-pass TIG and single-pass LBW, respectively. For the LBW, an I-type groove without gap was used, and in the following welding no filler metals were used. A $15 \mathrm{~kW}$ Han's fibre laser was employed and the welding head was attached to an ABB robot. In the TIG, a V-type groove with the angle of $30^{\circ}$ and the root face dimension of $1.5 \mathrm{~mm}$ was adopted. A 9-pass welding process was carried out and the inter-pass temperature was below $150{ }^{\circ} \mathrm{C}$. The filler material of TIG welding was ER308L. The chemical compositions of the base material and the filler material are listed in Table 1 . The detailed welding processing parameters of TIG and LBW are listed in Table 2.

\subsection{Slow Strain Rate Test}

After welding, rodlike samples with the gauge length of $25.4 \mathrm{~mm}$ and gauge diameter of $4 \mathrm{~mm}$ were sliced from welded pipelines along the axial direction, as shown in Fig. 1. The weld metal (WM) was placed at the centre of samples. Prior to testing, the samples were ground with abrasive papers to eliminate the machining defects and then cleaned by alcohol and deionized water, respectively.

The SCC susceptibility of joints was investigated by the SSRT with a strain rate of $4 \times 10^{-7} \mathrm{~s}^{-1}$ in air and the simulated PWR environment (oxygen-free), respectively. In the aqueous environment, the pressure was $11.5 \mathrm{MPa}$ and the test temperature was $350^{\circ} \mathrm{C}$. In air, the samples were heated to $350{ }^{\circ} \mathrm{C}$ and kept warm. During testing, the stress and strain dataset were recorded automatically. After failure, the

Table 1 Chemical compositions of base metal and filler (wt $\%$ )

\begin{tabular}{llllllllll}
\hline Materials & $\mathrm{C}$ & $\mathrm{Cr}$ & $\mathrm{Ni}$ & $\mathrm{Si}$ & $\mathrm{Mn}$ & $\mathrm{Mo}$ & $\mathrm{Cu}$ & $\mathrm{Nb}$ & $\mathrm{Fe}$ \\
\hline AISI 304 & 0.06 & 18.5 & 8.3 & 0.5 & 1.5 & 0.3 & 0.4 & 0.03 & Bal. \\
ER308L & 0.02 & 18.1 & 9.7 & 0.6 & 1.9 & 0.2 & 0.01 & 0.007 & Bal. \\
\hline
\end{tabular}

Table 2 Welding process parameters

\begin{tabular}{llllllll}
\hline Methods & Groove type & Weld pass & Filler & Power $(\mathrm{P} / \mathrm{kW})$ & $\begin{array}{l}\text { Welding speed } \\
\left(\mathrm{v} / \mathrm{mm} \mathrm{s}^{-1}\right)\end{array}$ & Shield gas & Heat input $\left(\mathrm{q} / \mathrm{kJ} \mathrm{mm}^{-1}\right)$ \\
\hline LBW & I-type & Single-pass & - & 11 & 8 & $\mathrm{~N}_{2}$ & 1.375 \\
TIG & $30^{\circ}$-V-type & Multi-pass & ER308L & 2.8 & 2.2 & Ar & 1.270 (one of nine passes)
\end{tabular}




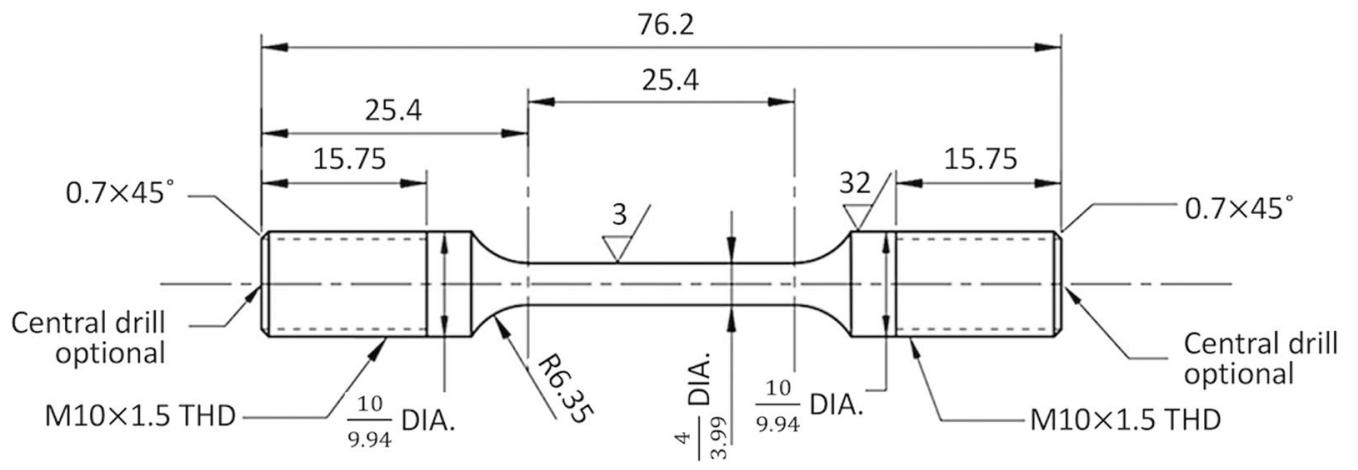

Fig. 1 Sketch of SSRT specimen (mm)

fractography of joints was observed on a JSM-7800F scanning electron microscope (SEM).

\subsection{Electrochemical Experiment}

To further verify the SCC susceptibility of the joints, an accelerated corrosion test in HAZs was carried out in 3.5 wt $\% \mathrm{NaCl}$ solutions. To find the HAZ exactly, firstly the joint surface was etched by using a mixture of $10 \%(\mathrm{~V} / \mathrm{V})$ nitric acid and $90 \%$ ethyl alcohol to distinguish the BM, HAZ and WM by the naked eye, and then the prepared sample was cut in the expected location, followed by abrasive paper sanding and mechanical polishing. Electrochemical tests were conducted in a conventional three-electrode cell using a CHI 660E electrochemical system. The saturated calomel electrode (SCE), Pt wire and the sample were used as the reference, auxiliary and working electrodes, respectively. Potentiodynamic polarization tests were performed over the applied potential ranging from $-1.0 \mathrm{~V}$ to $1.0 \mathrm{~V}$ at a sweep rate of $1 \mathrm{mV} \mathrm{s}^{-1}$. In order to investigate corrosion behaviour of joints in the aqueous environment, the characteristics of corrosion products on the surfaces of joints after electrochemical measurements were revealed by X-ray photoelectron spectroscopy (XPS) analysis on a Kratos AXIS ultra-photoelectron spectroscopy analyser with an $\mathrm{Al} K_{\alpha}$ excitation source. The spectrometer was operated with a constant pass energy of $30 \mathrm{eV}$. The $\mathrm{C} 1 s(284.8 \mathrm{eV})$, as the surface pollutant element, was required to calibrate the charge effect.

\subsection{Microstructure Characterization}

In order to investigate the influence of microstructure and residual strain on the SCC, the electron-backscattered diffraction (EBSD) test was carried out. Samples for EBSD observations were cut from the LBW and TIG joints. The samples were ground and polished mechanically, and then electrochemically polished at room temperature for $3 \mathrm{~min}$. The solution for electrochemical polishing was comprised of $10 \%(\mathrm{~V} / \mathrm{V}) \mathrm{HClO}_{4}$ and $90 \%$ (V/V) $\mathrm{CH}_{3} \mathrm{COOH}$. The voltage was set at $15 \mathrm{~V}$. The EBSD data were obtained at the AZtec HKL Max system under an accelerating voltage of $20 \mathrm{kV}$ and a step size of $8 \mu \mathrm{m}$.

In addition, the samples were ground and polished mechanically, then etched by $10 \%$ chromic acid for $30 \mathrm{~s}$ under $10 \mathrm{~V}$. The microstructures of WMs for the two joints were observed by an optical microscope with the help of image analysis software.

\section{Results}

\subsection{Mechanical Properties of the TIG Joint and LBW Joint}

The stress-strain curves of SSRT in both air and the simulated water environment are plotted in Fig. 2, and the yield strength, ultimate tensile strength and elongation are summarized in Table 3. It could be found that the yield strength, ultimate tensile strength and elongation of the LBW joint are significantly lower than those of the TIG

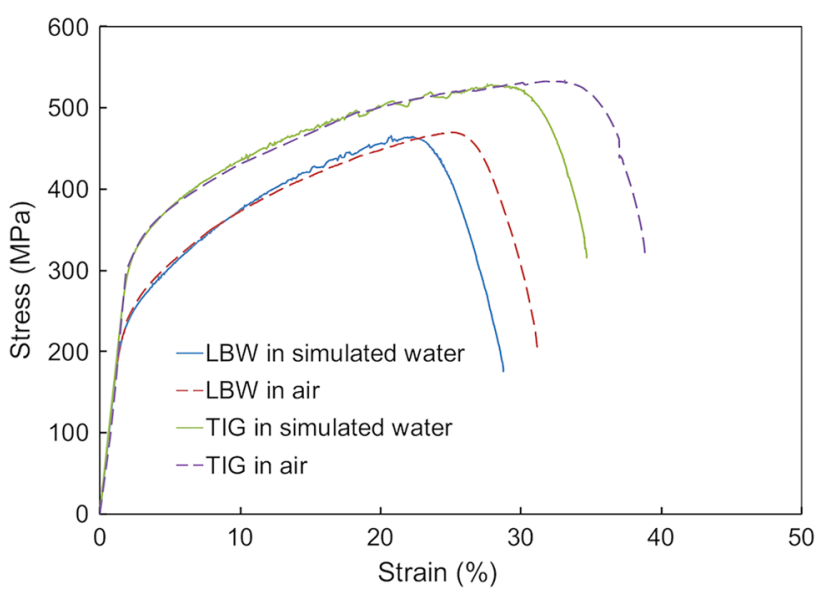

Fig. 2 Stress-strain curves of two joints in air and in simulated PRW environment 
Table 3 Corrosion properties of the two joints

\begin{tabular}{|c|c|c|c|c|c|c|c|}
\hline \multirow[t]{2}{*}{ Specimen } & \multicolumn{2}{|l|}{ In air } & \multicolumn{2}{|c|}{$\begin{array}{l}\text { In simulated primary } \\
\text { water }\end{array}$} & \multirow[t]{2}{*}{$I_{\sigma}(\%)$} & \multirow[t]{2}{*}{$I_{\eta}(\%)$} & \multirow[t]{2}{*}{ ISSRT $(\%)$} \\
\hline & $\sigma_{\mathrm{a}}(\mathrm{MPa})$ & $\eta_{\mathrm{a}}(\%)$ & $\sigma_{\mathrm{w}}(\mathrm{MPa})$ & $\eta_{\mathrm{w}}(\%)$ & & & \\
\hline LBW joint & 470 & 31.2 & 466 & 28.8 & 0.85 & 7.7 & 2.7 \\
\hline TIG joint & 534 & 38.9 & 529 & 34.7 & 1.12 & 9.4 & 3.9 \\
\hline
\end{tabular}

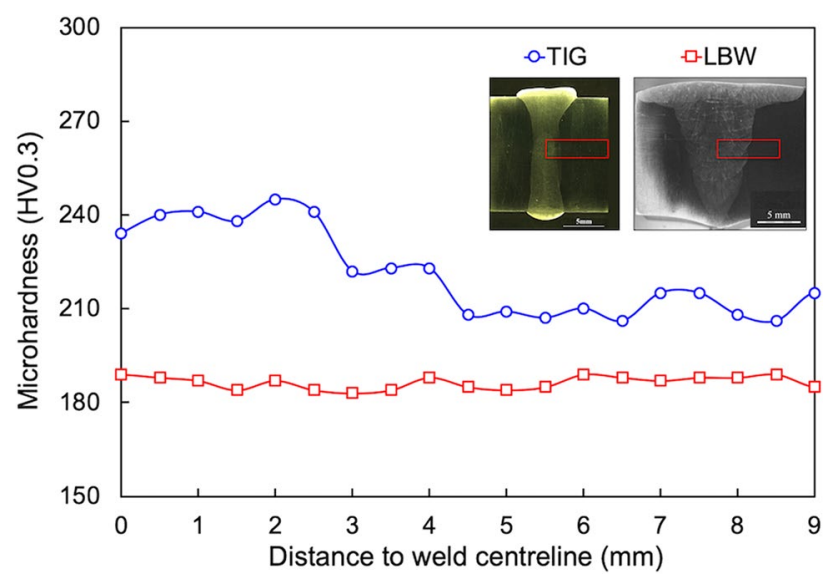

Fig. 3 Microhardness distribution along the transverse direction

joint under the two experimental conditions. The microhardness of the welded joints was measured by a Zwick automatic hardness tester, as shown in Fig. 3. According to the distribution of microhardness, the microhardness of the TIG joint is obvious higher than that of the LBW joint at the position having the same distance from the weld centreline. In addition, the microhardness of WM is the highest in the TIG joint, so the yield occurs earlier in the BM during SSRT. In contrast, the yield of the LBW joint takes place earlier in the WM. Therefore, higher elongation of the TIG joint should be attributed to good toughness of the BM. The markedly different hardness and strength of the two joints are explained in Sect. 4.

\subsection{SCC Susceptibility Comparison of TIG Joint and LBW Joint}

Generally, SCC resistance is often evaluated by the parameter $t_{\mathrm{f}}$ (time to failure) in corrosion environments. The larger the $t_{\mathrm{f}}$ in SSRT, the better the SCC resistance. However, because of non-uniform mechanical properties of welded joints, $t_{\mathrm{f}}$ cannot be used to evaluate the susceptibility of SCC. In this study, ultimate tensile strength-loss rate $\left(I_{\sigma}\right)$ and elongation-loss rate $\left(I_{\eta}\right)$ are calculated to evaluate the SCC susceptibility. The definitions of the relevant rates are expressed as follows:
$I_{\sigma}=\left(1-\frac{\sigma_{\mathrm{w}}}{\sigma_{\mathrm{a}}}\right) \times 100 \%$,

$I_{\eta}=\left(1-\frac{\eta_{\mathrm{w}}}{\eta_{\mathrm{a}}}\right) \times 100 \%$,

where $\sigma_{\mathrm{w}}$ and $\eta_{\mathrm{w}}$ are the ultimate tensile strength and elongation of joints in the simulated water environment, respectively. $\sigma_{\mathrm{a}}$ and $\eta_{\mathrm{a}}$ are the ultimate tensile strength and the elongation of joints in air, respectively.

The higher the $I_{\sigma}$ and $I_{\eta}$, the higher the SCC susceptibility. Table 3 lists the corrosion properties of the two joints. It is apparent that the values of $I_{\sigma}$ and $I_{\eta}$ for the TIG joint are slightly higher than those of the LBW joint. Therefore, the SCC susceptibility of the LBW joint is slightly lower than that of the TIG joint.

The stress corrosion index $\left(I_{\mathrm{SSRT}}\right)$ is an important criterion of SCC obtained by the SSRT tests, which can accurately reflect the SCC susceptibility. $I_{\mathrm{SSRT}}$ is calculated by Eq. (3). The values of $I_{\text {SSRT }}$ are also listed in Table 3. It can be found that the values of $I_{\mathrm{SSRT}}$ are very small, indicating that both the TIG and LBW joints have good stress corrosion resistance. The SCC resistance of $\mathrm{LBW}$ is somewhat higher than that of the TIG joint, in very good agreement with the variations of $I_{\sigma}$ and $I_{\eta}$.

$I_{\mathrm{SSRT}}=1-\left[\sigma_{\mathrm{w}} \times\left(1+\delta_{\mathrm{w}}\right)\right] /\left[\sigma_{\mathrm{a}} \times\left(1+\delta_{\mathrm{a}}\right)\right]$.

\subsection{Fracture Characteristics of the TIG Joint and LBW Joint}

Figure 4 presents the cross-sectional morphologies of the two fractured joints in the simulated water environment. The observations indicate that the fracture positions are located at the HAZs near the fusion lines of the two joints, and HAZs are thus considered as the focused positions at which the electrochemical measurements are carried out to verify the results of SSRT.

The fracture morphologies of the two joints in air are shown in Fig. 5. The fracture centres of the TIG joint and LBW joint show a lot of dimples, and the fracture edges exhibit clear ductile fracture characteristics. However, in the simulated PRW environment the fracture morphologies exhibit markedly different features, as shown in Fig. 6. 

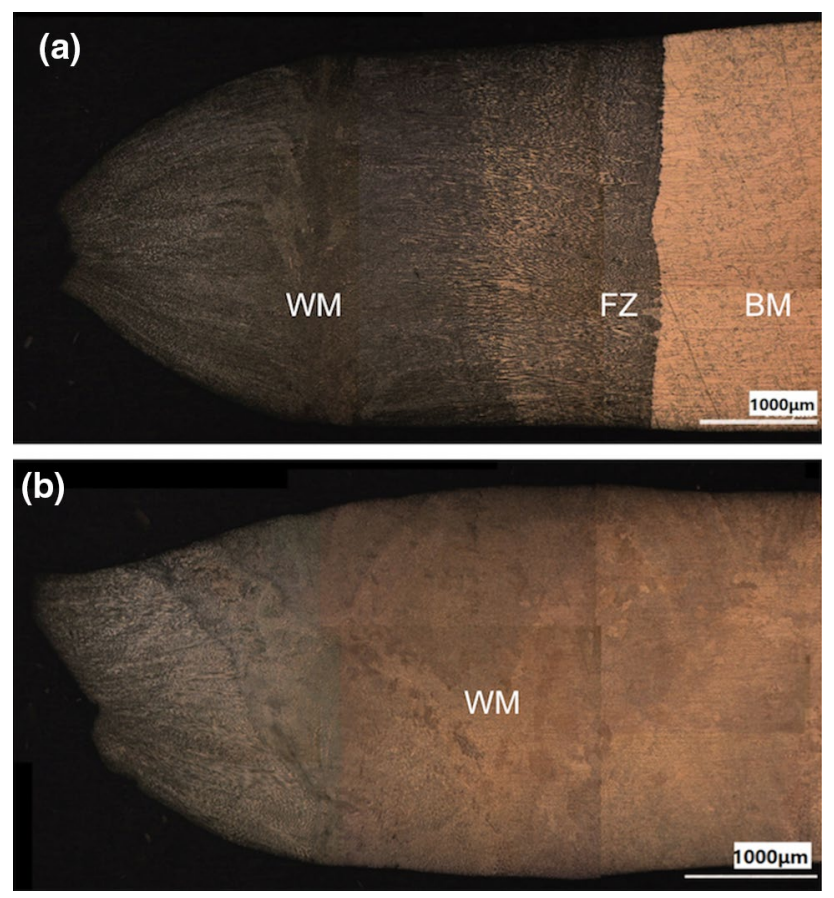

Fig. 4 Longitudinal fracture macrographs of $\mathbf{a}$ the LBW joint, $\mathbf{b}$ the TIG joint
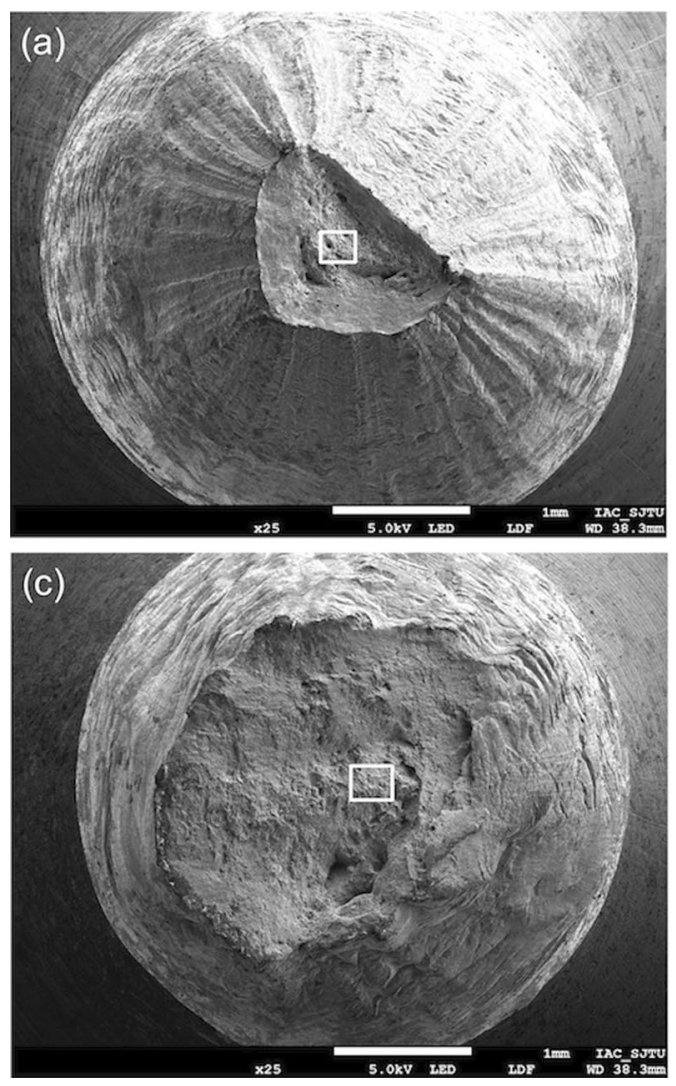

The fracture centres of the two joints are covered by plastic deformation dimples, which reveal the ductile fracture. But the fracture edges present the feature of brittle fracture, as typical SCC characteristics.

\subsection{Electrochemical Test}

The Tafel extrapolation method is used to calculate the corrosion potential $\left(E_{\text {corr }}\right)$ and corrosion current density ( $\left.I_{\text {corr }}\right)$. It is well known that a nobler $E_{\text {corr }}$ and a lower $I_{\text {corr }}$ mean higher corrosion resistance of materials [14]. Figure 7 shows the potentiodynamic polarization curves of the TIG and LBW joints. It can be seen that the $E_{\text {corr }}$ of LBW joint $(-406 \mathrm{mV})$ is slightly nobler than that of TIG joint $(-418 \mathrm{mV})$, and the $I_{\text {corr }}$ of LBW joint $\left(3.1 \times 10^{-6} \mathrm{~A} \mathrm{~cm}^{-2}\right)$ is lower than that of TIG joint $\left(4.3 \times 10^{-6} \mathrm{~A} \mathrm{~cm}^{-2}\right)$. With respect to the self-passivated alloys in corrosive environments, the passivation current density $\left(I_{\mathrm{P}}\right.$, for maintaining the passive state) was estimated and used to represent the corrosion rate of the two joints. The results show that the $\mathrm{HAZ}$ in the LBW joint displays a relatively low $I_{\mathrm{P}}\left(4.8 \times 10^{-6}\right.$ $\left.\mathrm{A} \mathrm{cm}^{-2}\right)$ in comparison with the TIG joint $\left(6.7 \times 10^{-6} \mathrm{~A}\right.$ $\mathrm{cm}^{-2}$ ). The relatively slow corrosion rate of the LBW joint implies its high resistance to corrosion.
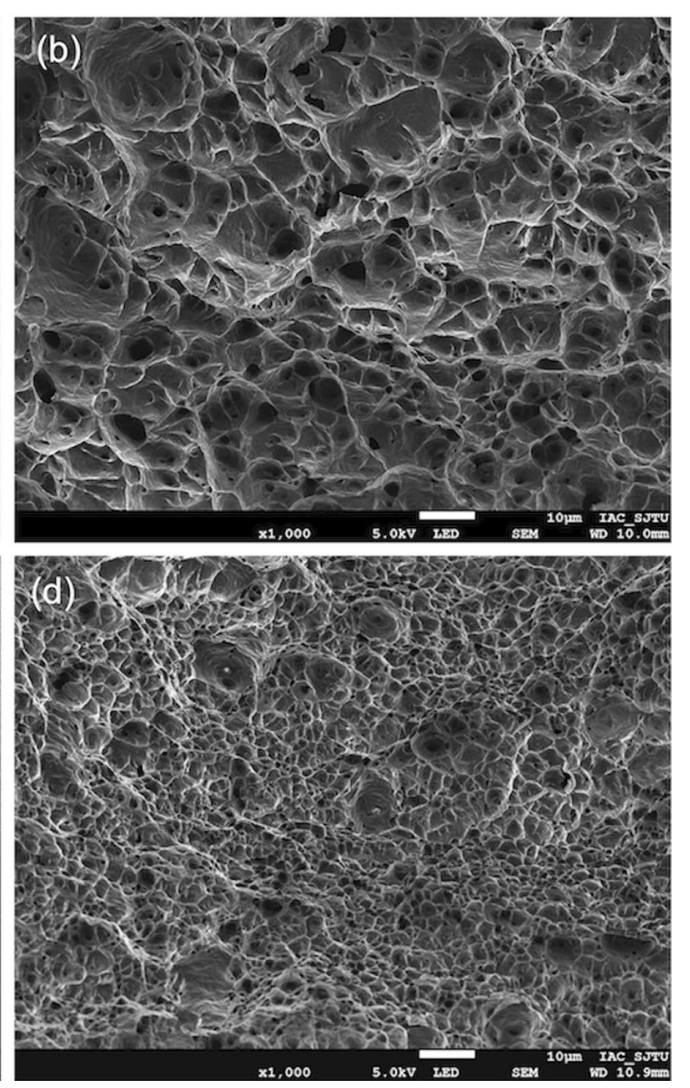

Fig. 5 SEM fractographs in air: a overview of the LBW joint, $\mathbf{b}$ at the rim area of the LBW joint, $\mathbf{c}$ overview of the TIG joint, $\mathbf{d}$ at the rim area of the TIG joint 

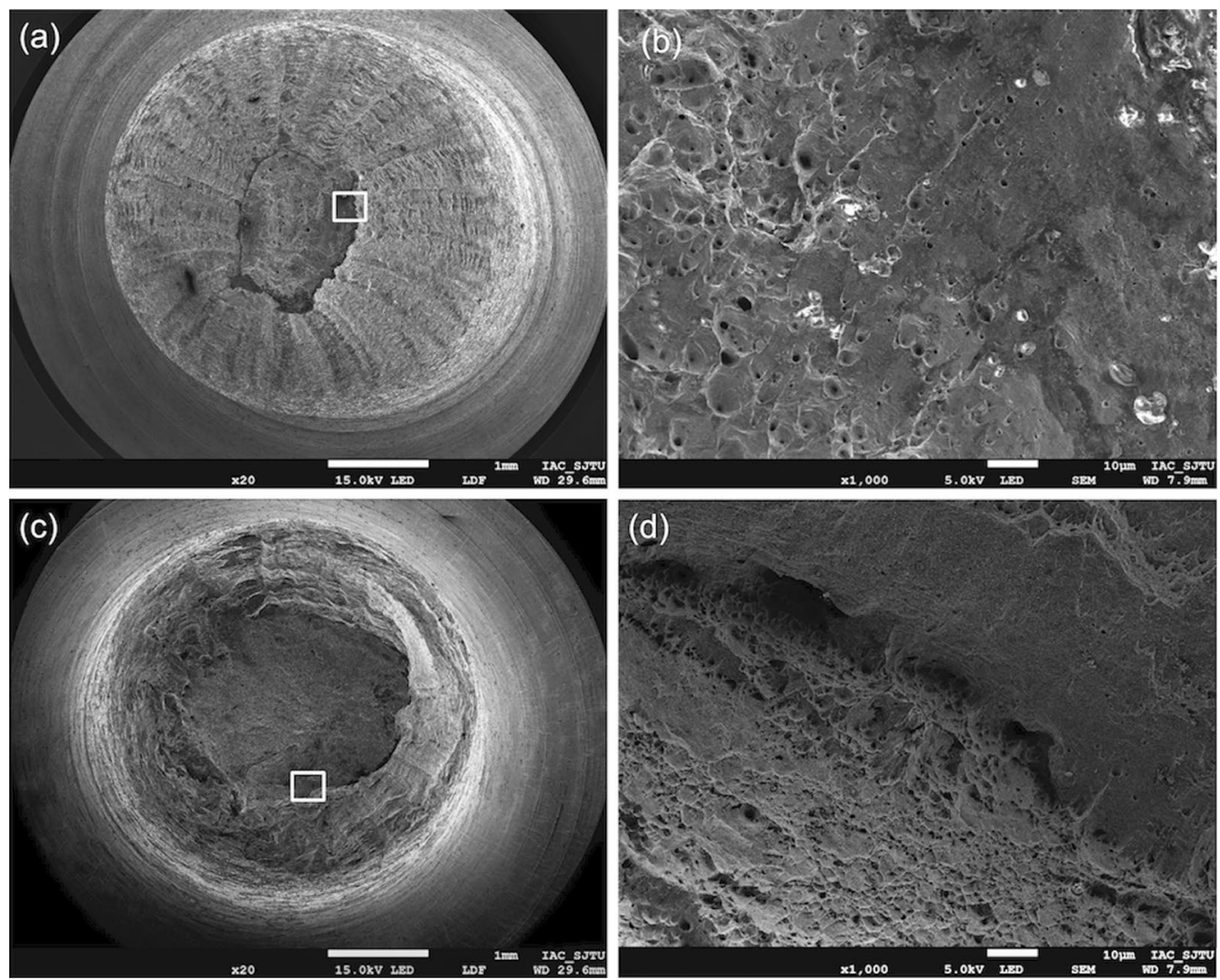

Fig. 6 SEM fractographs in simulated PRW environment: a overview of the LBW joint, $\mathbf{b}$ at the rim area of the LBW joint, $\mathbf{c}$ overview of the TIG joint, $\mathbf{d}$ at the rim area of the TIG joint

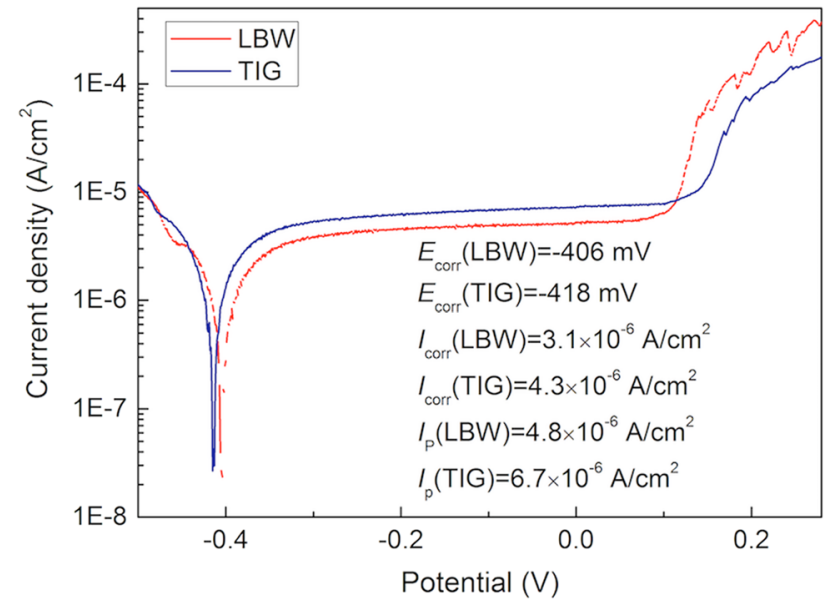

Fig. 7 Potentiodynamic polarization curves of the welded joints

\section{Discussion}

The TIG and LBW joints show different SCC susceptibility in the simulated PRW environment. In order to explain this phenomenon, the effects of factors including microstructures, residual strain and the formed corrosion products on corrosion resistance are discussed in detail.

\subsection{Microstructure}

To investigate the difference of microstructure between the LBW and TIG joints, EBSD was conducted to calculate the average grain size and grain orientation. The inverse pole figure (IPF) maps of the two joints are depicted in Fig. 8. The BM is made of finer grains with a random orientation and an average grain size of 10-20 $\mu \mathrm{m}$. Significant columnar dendrites are observed in the WM regions of the two joints and grow along the direction opposite to the heat transfer direction, particularly a high length-to-width ratio of columnar grains formed in the LBW joint, as shown in Fig. 8a, b. Due to the faster heat dissipation in vertical direction of the fusion line, it is easier to form dendrites. As a result, dendrites grow from the fusion line to WM in the LBW joint, while they grow from the fusion line of the former pass to that of the latter pass in the multi-pass TIG joint and thus display a relative low length-to-width ratio of columnar grains. These observations are in good agreement with the IPF maps where the two joints exhibit (200) preferred orientations, particularly a more significant texture for the 

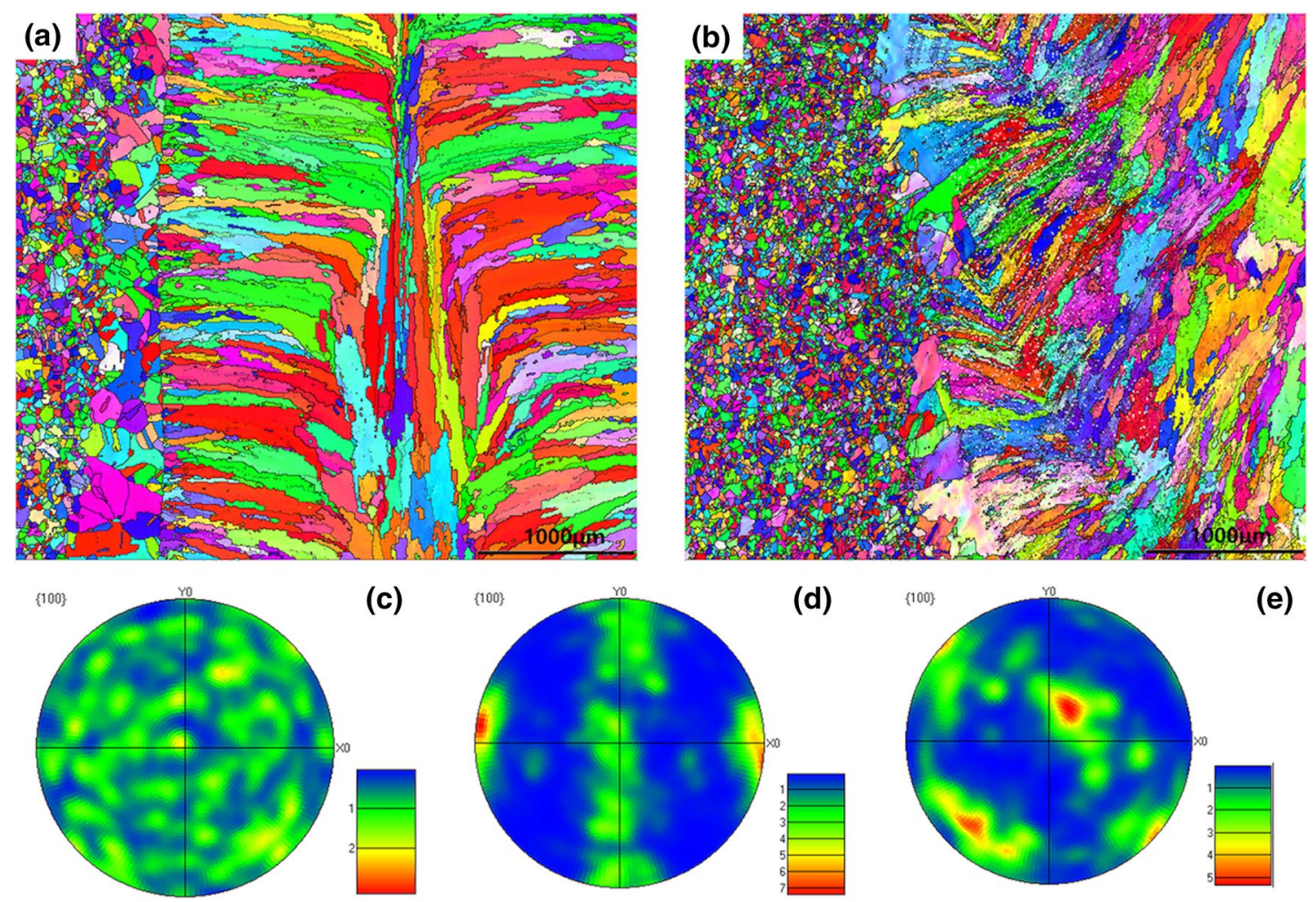

(e)

Fig. 8 IPF maps of a the LBW joint, $\mathbf{b}$ the TIG joint, (100) pole figures of $\mathbf{c}$ the BM of AISI 304 steel, $\mathbf{d}$ the LBW weld metal and $\mathbf{e}$ the TIG weld metal

LBW joint (Fig. 8d, e). The difference in texture strength of the joints arises from the varying pass for the LBW and TIG techniques, and the latter is featured by a 9-pass welding process in which the adjacent passes can interrupt the continuing growth of the dendrite.

The EBSD results show that significantly different grain sizes can be found for either WM or HAZ in the LBW and TIG joints. Specifically, WM of the LBW joint has an average grain size (about $71 \mu \mathrm{m}$ ) larger than that of the TIG joint (about $35 \mu \mathrm{m}$ ); on the contrary, the average grain size in HAZ of the LBW joint is smaller than that of the TIG joint. It has been well established that the smaller grain size could promote the formation of compact passive films and the enrichment of $\mathrm{Cr}_{2} \mathrm{O}_{3}$ in the passive film, which enhance SCC resistance significantly [15-17]. In our case, the LBW joint possessing superior SCC resistance in the simulated PWR environment can be ascribed to the relatively small grain size of HAZ which does act as the fracture position.

In addition, the SCC susceptibility is related with the content of $\delta$-ferrite. Abundant $\delta$-ferrite phase can decrease the SCC susceptibility effectively [18]. The stress corrosion crack can be retarded by the $\delta / \gamma$ interface, which results in high corrosion cracking resistance [19]. From the phase distribution in Fig. 9, $\delta$-ferrite (red colour) mainly distributes in WM regions of joints. The ferrite will precipitate at the austenite grain boundaries during the cooling process because the solidification process in welding is rapid and non-equilibrium, and the temperature in the fusion zone is higher than the $\delta-\gamma$ balance temperature [4]. As seen from Fig. 9c and d, the ferrite is typically vermicular and distributes along austenite grain boundaries. In the WM region of the TIG joint, more $\delta$-ferrite can be observed clearly. The ferrite content is considered to be closely related to the total heat input of the welding techniques. The total heat input of the TIG (featured by a 9-pass welding process) is certainly larger than that of the LBW, though a slightly low heat input for the singlepass TIG. A multi-pass welding process can increase the interlayer temperature, thereby lowering the cooling rate. Consequently, the TIG technique with a low cooling rate facilitates the ferrite precipitation. Moreover, the ferrite content is one of the key factors affecting the hardness and strength of stainless steels. Generally, the higher the ferrite content, the higher the hardness and strength [8]. The finding is in good agreement with higher hardness and strength of the TIG joints. However, there is less $\delta$-ferrite located in the HAZ of TIG joint than that of LBW joint, in accordance with the fracture position. In addition, there is obvious grain coarsening in HAZs of the two joints, and the HAZ is therefore the most susceptible region to SCC. 

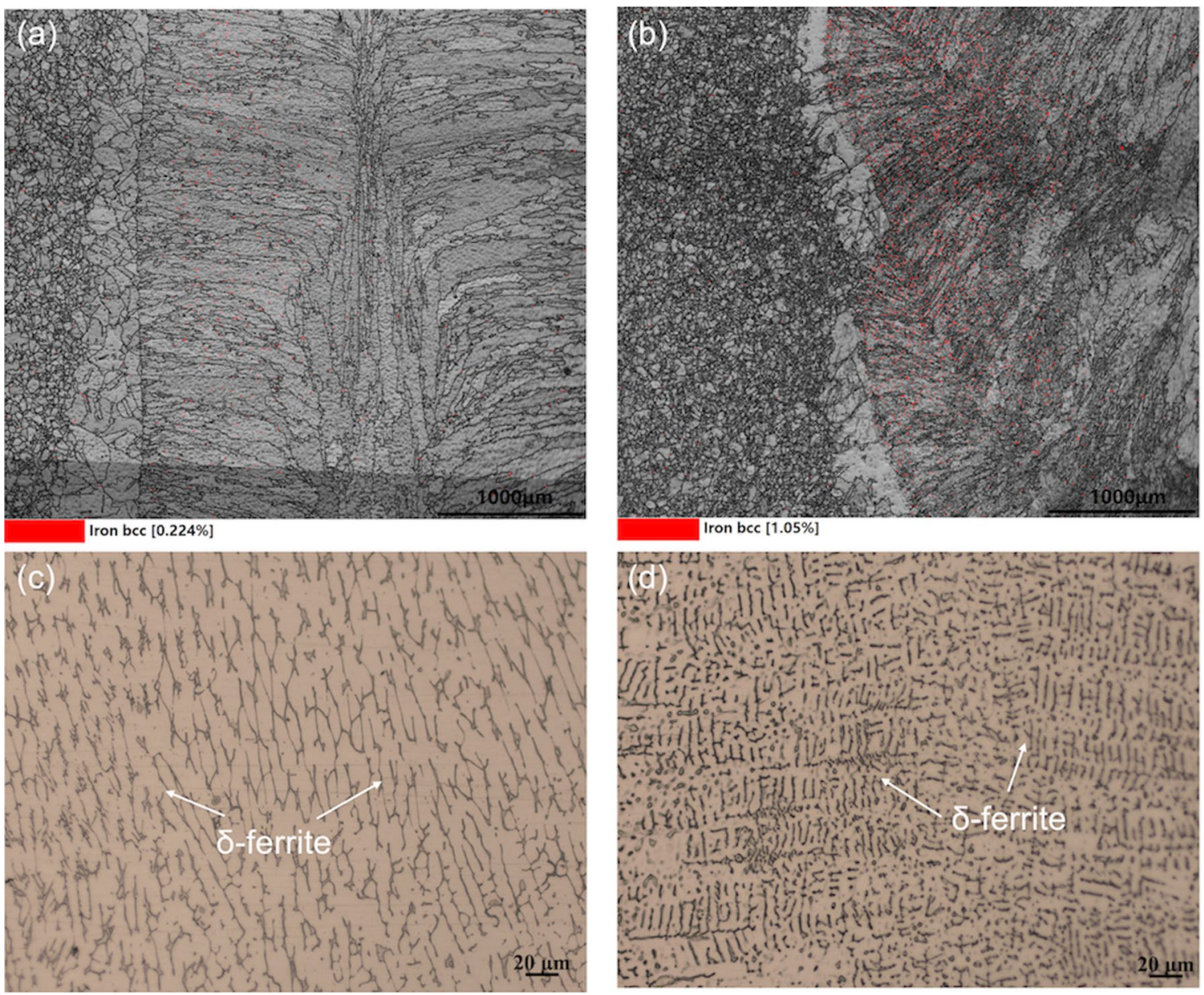

Fig. $9 \delta$-Ferrite distribution in a the LBW joint, $\mathbf{b}$ the TIG joint; optical microphotographs for $\mathbf{c}$ the LBW joint, $\mathbf{d}$ the TIG joint

\subsection{Residual Strain}

Residual strain also plays an important role in the SCC behaviour of welding joints and can increase the SCC susceptibility $[19,20]$. Moreover, the crack growth rate can be expedited by residual strain [21]. In Fig. 10, the kernel average misorientation (KAM) maps are used to estimate the residual strain of the two joints. It can be found that the TIG joint presents higher KAM intensities in WM and HAZ comparing with the LBW joint, implying higher overall residual strain in the TIG joint resulted from strain hardening of the multi-pass welding process. Therefore, the TIG joint has higher SCC susceptibility than the LBW joint. Meanwhile, the varying degree of strain hardening leads to different hardness of HAZs for the two joints.

\subsection{Corrosion Products}

In austenitic stainless steels, $\mathrm{Cr}$ can improve the SCC resistance. The $\mathrm{Cr}$ enrichment in passive films is of great help for enhancing corrosion resistance because of the formation of
$\mathrm{Cr}_{2} \mathrm{O}_{3}$ during the corrosion process [22-24]. Figure 11 shows the XPS spectra of different elements in passive films of the two joints. The characteristic spectra of $\mathrm{Cr} 2 p, \mathrm{Fe} 2 p$ and $\mathrm{O} 1 s$ elements are marked, respectively. The $\mathrm{Cr} 2 p_{3 / 2}$ spectra show a broad distinct peak of $576.7 \mathrm{eV}$ which is accordant with the binding energy of $\mathrm{Cr}^{3+}$ [25]. It can be considered that the corresponding oxide is $\mathrm{Cr}_{2} \mathrm{O}_{3}$ [26]. The $\mathrm{Fe} 2 p_{3 / 2}$ spectra are characterized by a distinct peak of $710.7 \mathrm{eV}$ corresponding to the binding energy of $\mathrm{Fe}^{3+}$, which is assigned to the oxide, $\mathrm{Fe}_{2} \mathrm{O}_{3}$ or $\mathrm{FeOOH}$. The Ni $2 p_{3 / 2}$ spectra present a major peak at $855 \mathrm{eV}$ and a satellite peak at $861 \mathrm{eV}$, corresponding to $\mathrm{Ni}(\mathrm{OH})_{2}$ in the oxide films. The $\mathrm{O}$ element exists in the oxide film as the forms of $\mathrm{O}^{2-}$ with the binding energy of $531.5 \mathrm{eV}$ and $\mathrm{OH}^{-}$represented by the $530 \mathrm{eV}$ peak. The XPS results indicate that more $\mathrm{Cr}_{2} \mathrm{O}_{3}$ is formed on the LBW joint. $\mathrm{Cr}_{2} \mathrm{O}_{3}$ is thought to be a compact oxide which can effectively hinder the penetration of electrolytes, and thus LBW joint exhibits better corrosion resistance than the TIG joint. More importantly, for the stainless steel subjected to corrosion in the simulated PRW environment, a multilayer oxide film could be formed on the exposed surface, i.e., Fe-rich oxide particles/Fe-rich 

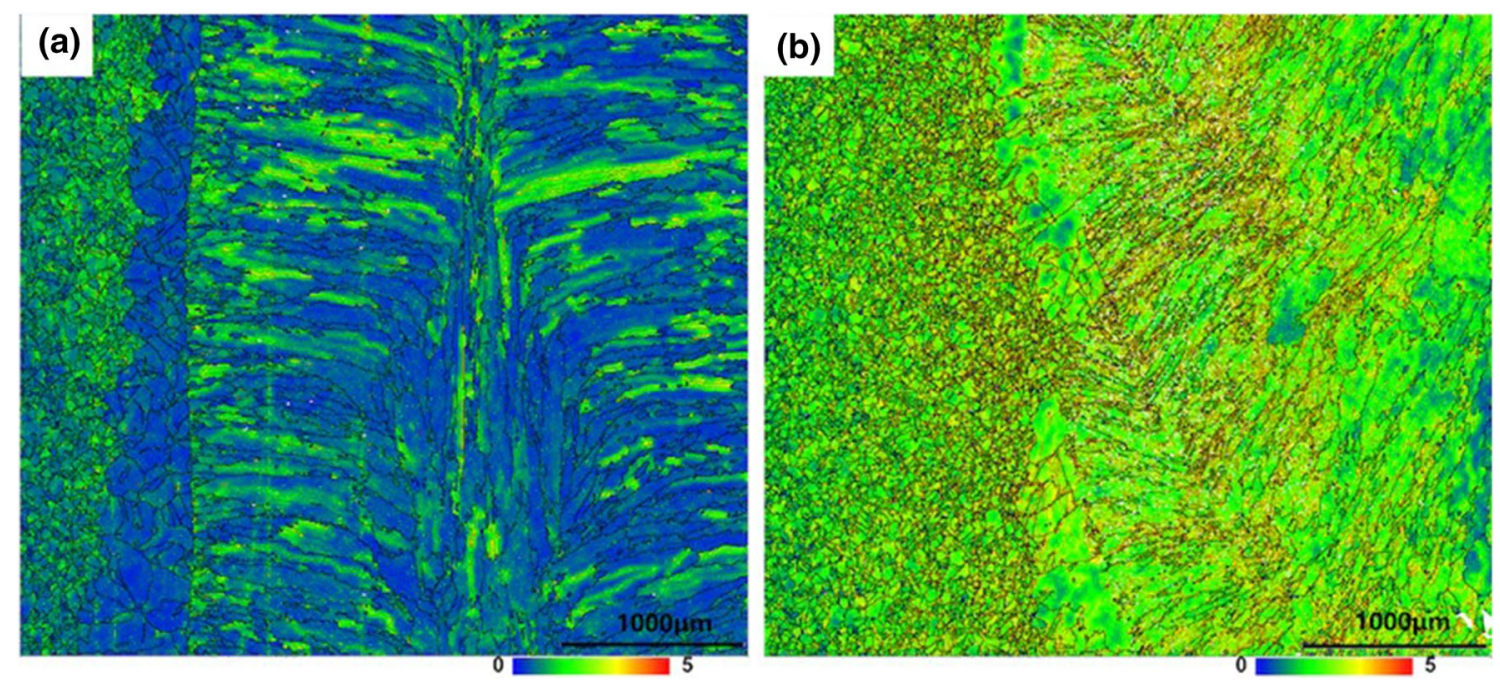

Fig. 10 EBSD KAM maps of a the LBW joint, $\mathbf{b}$ the TIG joint

oxide layer/Cr-rich oxide layer/Ni-rich penetrative oxidation layer, from the top to bottom (matrix). Among these layers, the $\mathrm{Cr}$-rich oxide plays a vital role on resisting oxide rupture. As corrosion proceeds, the dissolution of $\mathrm{Cr}$ from the inner oxide layer into the environment leads to a $\mathrm{Cr}$-depleted upper part, which eventually turns amorphous and has been referred to as the outer oxide layer. This new layer is not stable and starts to dissolve in high-temperature water. At some point, it loses its protective nature and oxidation starts to propagate deeper into the matrix [27-29]. Therefore, owning to the positive effect of $\mathrm{Cr}_{2} \mathrm{O}_{3}$ on the SCC resistance, the TIG joint containing less $\mathrm{Cr}_{2} \mathrm{O}_{3}$ is more vulnerable to oxide rupture and has higher SCC susceptibility in the simulated PRW environment.

In a word, the LBW joint exhibits better SCC resistance than the TIG joint in corrosion environments due to the synthetic effect of more $\mathrm{Cr}_{2} \mathrm{O}_{3}$ in corrosion films, finer grain, lower residual strain and higher $\delta$-ferrite content in the HAZ. In our previous work, due to less total heat input, the welding deformation and residual stress of the LBW joint are much lower than those of the TIG joint. Moreover, the single-pass LBW has superior production efficiency compared with the multi-pass TIG welding. Therefore, considering the SCC susceptibility, the residual stress, deformation and production efficiency, the LBW is more advantageous than the TIG for the welding of AISI 304 stainless steel pipes in the nuclear power industry.

\section{Conclusions}

1. Based on SSRT and the electrochemical corrosion, we proposed a comprehensive method to evaluate the SCC susceptibility of the TIG and LBW joints and discussed the influence factors on the resistance to SCC including the grain size, residual strain, the $\delta$-ferrite content and passive film composition. Although the TIG joint has good mechanical property, we analysed the feasibility of LBW instead of TIG in the nuclear power industry by considering the SCC susceptibility, production efficiency and the welding deformation.

2. The LBW joint owns higher corrosion resistance than the TIG joint in the simulated PRW environment, which can be attributed to the synthetic effect of the residual strain, grain size, the $\delta$-ferrite content and the composition of corrosion products.

3. In terms of the SCC susceptibility, the residual stress, deformation and production efficiency, the LBW is more advantageous than the TIG for the welding of AISI 304 stainless steel pipes in the nuclear power industry. 

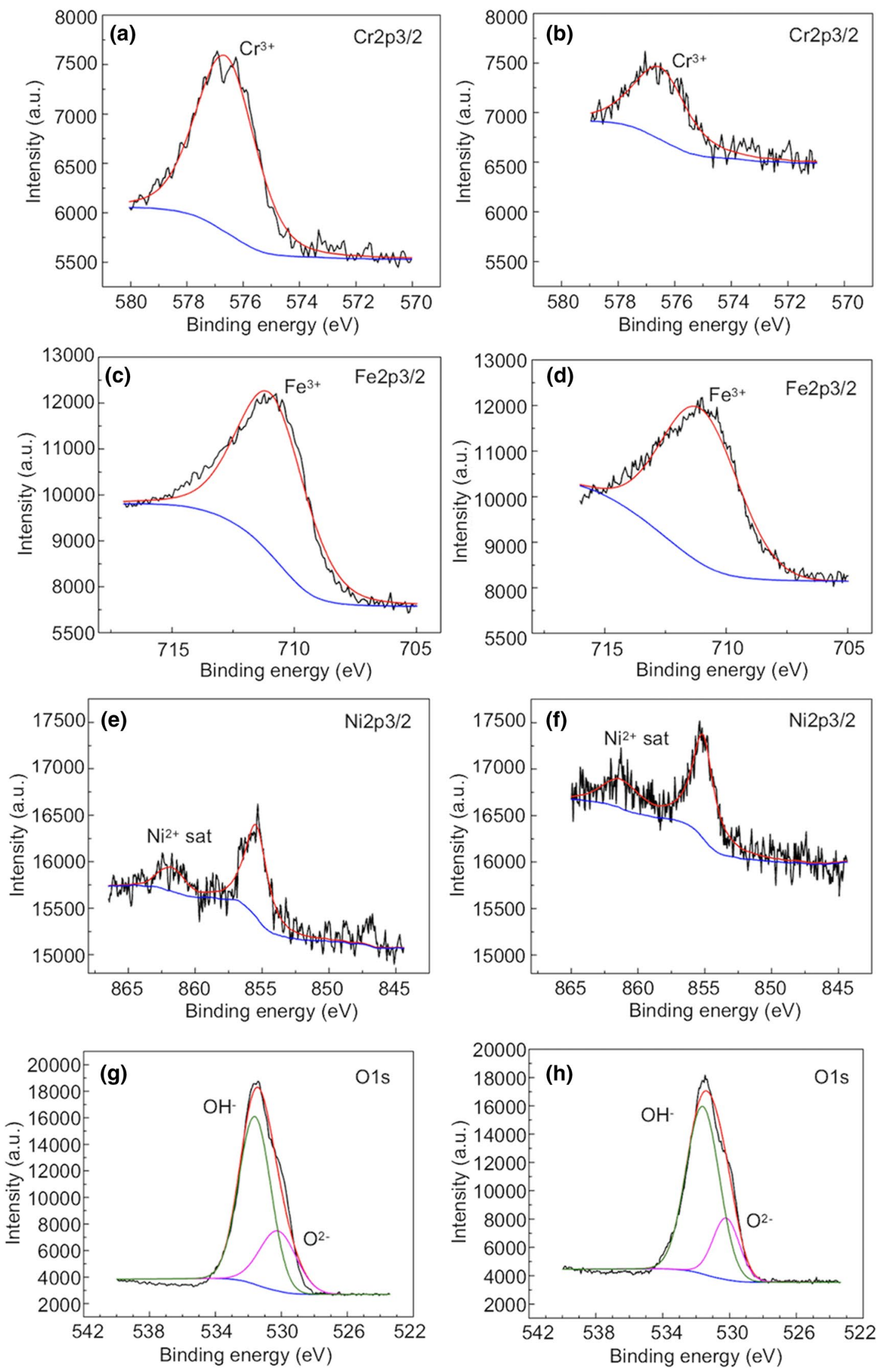
4Fig. 11 XPS high-resolution spectra of different elements in the oxide film: a Cr $2 p$ of the LBW joint, $\mathbf{b} \mathrm{Cr} 2 p$ of the TIG joint, $\mathbf{c}$ Fe $2 p$ of the LBW joint, $\mathbf{d}$ Fe $2 p$ of the TIG joint, e Ni $2 p$ of the LBW joint, $\mathbf{f}$ Ni $2 p$ of the TIG joint, $\mathbf{g ~ O} 1 s$ of the LBW joint, h O $1 s$ of the TIG joint

Acknowledgements This work was financially supported by the National Natural Science Foundation of China (No. 51405297).

\section{References}

[1] H.L. Ming, Z.M. Zhang, P.Y. Xiu, J.Q. Wang, E.H. Han, W. Ke, M.X. Su, Acta. Metall. Sin. (Engl. Lett.) 29, 848 (2016)

[2] S. Sabooni, F. Karimzadeh, M.H. Enayati, A.H.W. Ngan, H. Jabbari, Mater. Charact. 109, 138 (2015)

[3] J.M. Sun, X. Liu, Y. Tong, D. Deng, Mater. Des. 63, 519 (2014)

[4] J. Yan, M. Gao, X. Zeng, Opt. Lasers Eng. 48, 512 (2010)

[5] C.A. Loto, Int. J. Adv. Manuf. Technol. 93, 3567 (2017)

[6] G.J. Abraham, V. Kain, G.K. Dey, V.S. Raja, Corros. Sci. 93, 1 (2015)

[7] G.J. Abraham, R. Bhambroo, V. Kain, G.K. Dey, V.S. Raja, J. Mater. Eng. Perform. 22, 427 (2012)

[8] A.-H.I. Mourad, A. Khourshid, T. Sharef, Mater. Sci. Eng. A 549, $105(2012)$

[9] I.A. Orsi, L.B. Raimundo, O.L. Bezzon, M.A.A. Nobilo, S.E. Kuri, C.A.D. Rovere, V.O. Pagnano, J. Prosthodontics 20, 628 (2011)

[10] X. Xie, D. Ning, B. Chen, S. Lu, J. Sun, Corros. Sci. 112, 576 (2016)

[11] J.Z. Lu, H. Qi, K.Y. Luo, M. Luo, X.N. Cheng, Corros. Sci. 80, 53 (2014)
[12] P. De Tiedra, Ó. Martín, Mater. Des. 49, 103 (2013)

[13] J.J. Xu, J.Y. Chen, Y. Duan, C. Yu, J.M. Chen, H. Lu, J. Mater. Process. Technol. 248, 178 (2017)

[14] Z. Chai, C. Jiang, Electrochim. Acta 294, 11 (2019)

[15] Y. Tsuchiya, F. Kano, N. Saito, M. Ookawa, J. Kaneda, N. Hara, Corrosion and SCC properties of fine grain stainless steel in subcritical and supercritical pure water, in Paper Presented at the Corrosion 2007, Nashville, 11-15 March 2007

[16] K. Kako, Y. Miyahara, T. Arai, M. Mayuzumi, Denryoku Chuo Kenkyusho Hokoku 16, 1 (2009)

[17] J. Hou, Q.J. Peng, Z.P. Lu, T. Shoji, J.Q. Wang, E.H. Han, W. Ke, Corros. Sci. 53, 1137 (2011)

[18] Y. Chen, B. Alexandreanu, W.Y. Chen, K. Natesan, Z. Li, Y. Yang, A.S. Rao, J. Nucl. Mater. 466, 560 (2015)

[19] H. Abe, Y. Watanabe, J. Nucl. Mater. 424, 57 (2012)

[20] C. Ma, Q.J. Peng, J.N. Mei, E.H. Han, W. Ke, J. Mater. Sci. Technol. 34, 1823 (2018)

[21] Z.P. Lu, J.J. Chen, T. Shoji, Y. Takeda, S. Yamazaki, J. Nucl. Mater. 465, 471 (2015)

[22] R.K. Gupt, N. Birbills, Corros. Sci. 92, 1 (2015)

[23] M. Kanzaki, Y. Masaki, T. Kudo, Corrosion 71, 1027 (2015)

[24] J.L. Lv, T.X. Liang, C. Wang, L.M. Dong, Mater. Sci. Eng. C 360, 403 (2016)

[25] A.A. Hermas, Corros. Sci. 50, 2498 (2008)

[26] E. Unveren, E. Kemnitz, S. Hutton, Surf. Interface Anal. 36, 92 (2004)

[27] Z. Shen, D. Du, L. Zhang, S. Lozano-Perez, Corros. Sci. 148, 213 (2019)

[28] L. Fan, Z. Liu, W. Guo, J. Hou, C. Du, X. Li, Acta. Metall. Sin. (Engl. Lett.) 7, 866 (2015)

[29] J. Shao, C. Du, X. Zhang, L. Cui, Acta. Metall. Sin. (Engl. Lett.) 32, 89 (2019) 